\title{
Study on the Reform of Mechanical Professional Practice Teaching under the Background of Engineering Certification
}

\author{
Dongya Yang ${ }^{a}$, Tao Shen ${ }^{b}$, Runlan Guo ${ }^{c}$, Xiaozheng Xie ${ }^{d}$ and Zhaohui Li ${ }^{\mathrm{e}}$ \\ School of Mechanic-Electronic Engineering, Lanzhou University of Technology, \\ Lanzhou 730050, China;

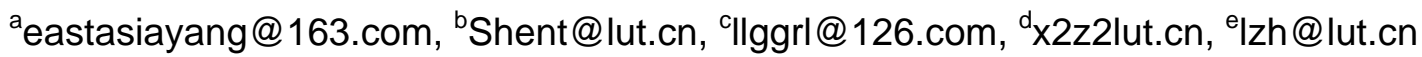
Keywords: Teaching reform, Engineering certification, Inquiry-Reception type leaning,
CAD/CAE/CAM.

\begin{abstract}
Before the engineering certification, in the link of mechanical professional practice teaching, especially in professional basic course design and graduation design, the teaching method was still remained in the passive learning mode that the teacher assigned task and the students follow specified steps, the implementation method was limited to artificial calculation and manual drawing. For the above problem of behindhand teaching methods and means, combining with the basic requirements of the mechanical engineering certification, an innovative reform is created, namely the inquiry-reception type teaching idea based on the driven project is introduced in the organization of the practice teaching and the integrated implementation method of CAD/CAE/CAM technology based on the mechanical product development process is adopted. Practice results show that the reform better achieves such objectives as the optimization of mechanical professional teaching system, knowledge structure and essential skills, and the development of the students' comprehensive practical ability, problem-solving ability and team cooperation ability, etc. The reform deepens the students' understanding and mastering of the integration of design and manufacturing technology based on the unified product data information, improves the students' ability of using CAD/CAE/CAM technology to solve the product development problems, and enhances the students' employment competitiveness. Therefore, the reform has certain value of reference and transplantation for other professional engineering certification.
\end{abstract}

\section{Introduction}

At present, the students' cultivation mode and its current situation of mechanical design and manufacturing and its automation major is in line with the requirements of engineering education professional certification standards, and can successfully accomplish the job of undergraduate course education based on engineering education professional certification standards in our school. But it is found by engineering education accreditation work that in the construction aspect of professional practice teaching link also has some following disadvantages.

The first disadvantage is that the practice teaching is still adopt the traditional model of product development mode and its content is mostly repetitive or list of previous teaching content and knowledge theory, the engineering and scientific research project is not systematically blended into the practice teaching, thus resulting in the students' engineering background is not strong and the degree of comprehensive training is not enough.

The traditional development method of mechanical products has the following characteristics, namely links of design, manufacture and testing are independent, and disconnect, so the design process must be repeats trial-manufacture, testing and modification for the product prototype, as shown in Fig. 1. As a result, some serious structural defects and errors of design principle and basic parameters cannot be found timely in the design phase. Some errors and defects will be found until the stage of final design or formal production and even after put into use for a period of time. Sometimes, the product will have to return to design construction phase in order to make the necessary changes. The product development process is low efficiency and wastes a lot of time, manpower and money. 


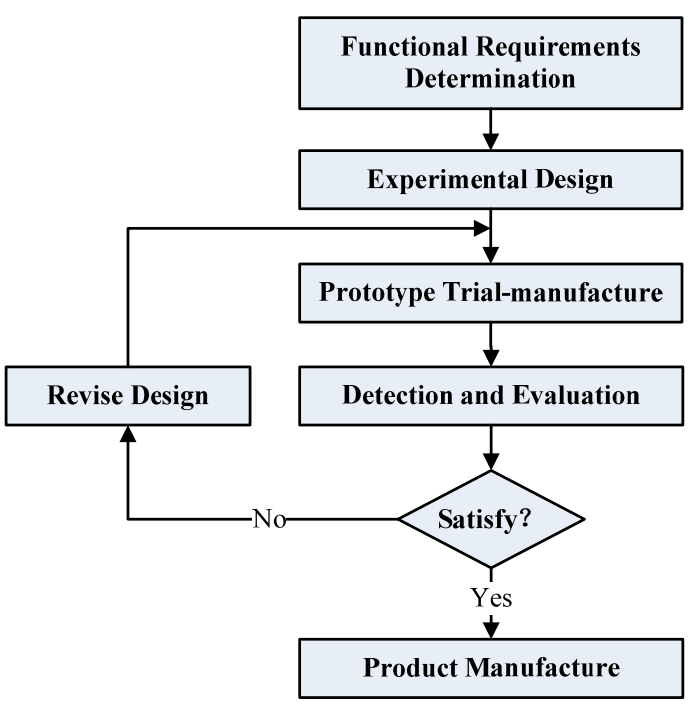

Fig. 1 Traditional product development process

The second disadvantage is that the teaching method was still remained in the passive learning mode that the teacher assigned task and the students follow specified steps.

The third disadvantage is that the implementation method was limited to artificial calculation and manual drawing; the CAD/CAE/CAM technology was not well used [1].

Mechanical CAD/CAE/CAM technology is a multidisciplinary comprehensive application technology with the rapid development of computer hardware and software technology and mechanical design and manufacturing technology, the carrier of modern virtual digital product design and also the foundation of advanced manufacturing technology. Mechanical CAD/CAE/CAM technology is an important technology of the enterprise technology innovation and market development. It has been widely used in the product development process of machinery, electronics, automobile, shipbuilding, aviation, aerospace and other fields. Its development and application level has become a measure of a country and one of the important symbols of the levels of enterprise technology. It is a basic technology must be mastered for engineering students and engineering technical personnel.

So, the students' passive learning mode in the process of course design needs to change, the regular practice teaching plan needs reform and follow the enterprise actual product development route, so as to deepen students' understanding and master of the relevant theoretical knowledge, to improve students' ability of applying mechanical CAD/CAE/CAM technology to solve practical product development problem, and to enhance the students' employment competitiveness.

\section{Reform measures}

In the teaching process, knowledge cannot presented to students only in the form of finalize the design, and in a larger extent, need to be found in solving problems by students themselves. To understand the knowledge formation and to form knowledge structure based on the internal relation of the explored knowledge and other related knowledge, there must be a process of internalization that is the construction process of accepting the significance of learning. It is thus clear that in teaching process, especially in the practice teaching process, teachers should moderate the balance of inquiry learning and reception learning. According to different points of curriculum knowledge and skills, teachers should guide students to combine inquiry learning with other learning way to receive the best learning effect.

In the process of guiding machinery professional foundation course design and graduation design, the inquiry-reception type compound teaching idea based on the driven project is introduced in the organization of the practice teaching, as Fig. 2 shown [2, 3]. According to this method, three core of teaching work, namely teaching content, teaching method and examination method, are designed as a closed loop feedback system with adaptive ability. This way achieves good teaching effect. 


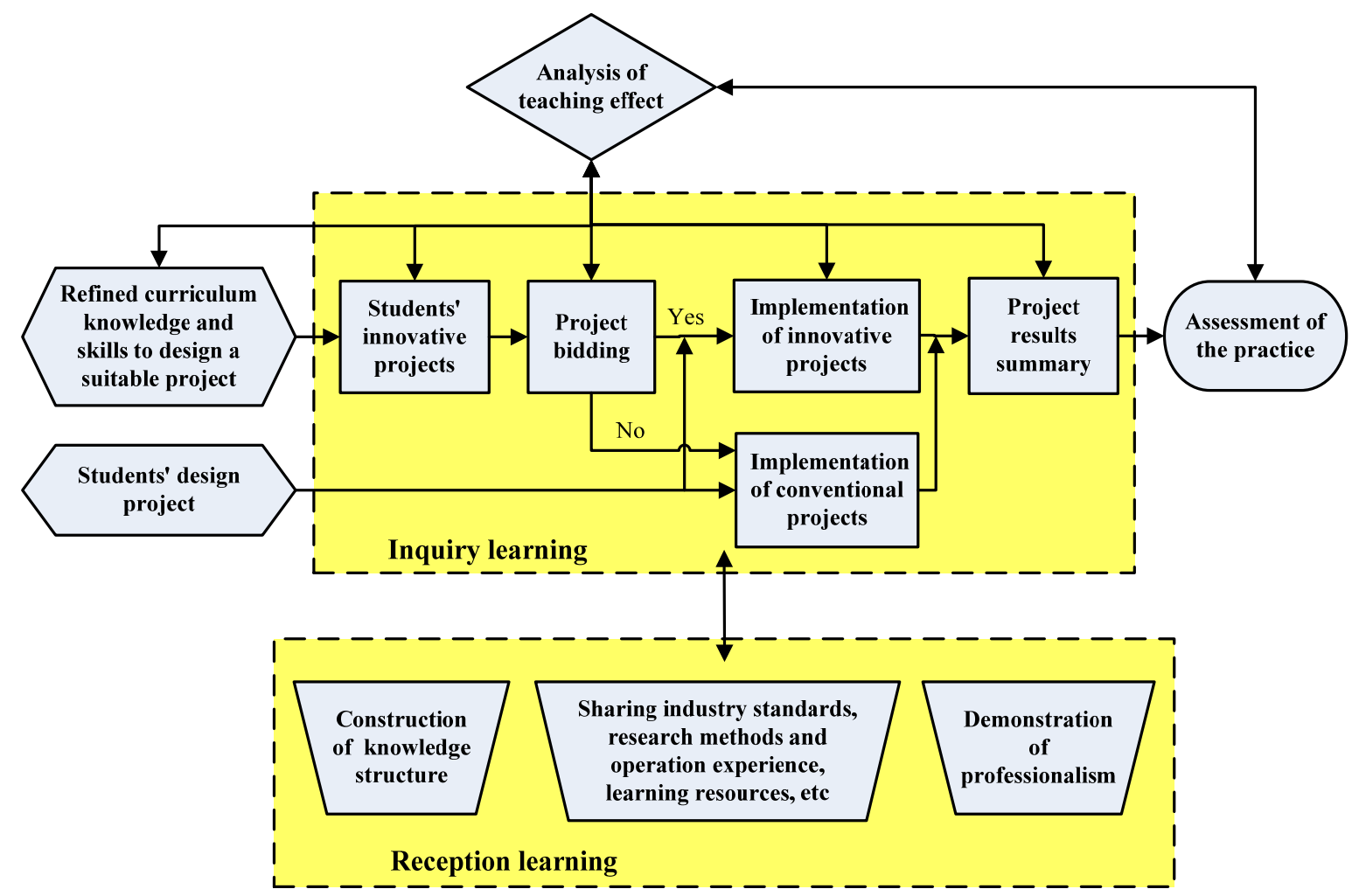

Fig. 2 The implementation plan of the inquiry - reception type compound teaching idea based on the driven project

Teaching contents. The core of the reform plan for teaching content is to establish a suitable project library. The evaluation index of the project library includes the abundance of the project content, the correlation of engineering background, and the comprehensiveness of the training that combining theory with practice, as well as the fulfilling degree for the standard of mechanical engineering certification. The subject of the project library construction can be either the teacher of teaching groups, can also be students themselves. The project design method is that firstly analyzing the requirements of the curricular knowledge and skills, and designing a series of systemic project group including the relevant elements as much as possible, so that really strengthening the students' application ability of mechanical professional foundation course in the process of exploring project. The purpose of the project classification that is conventional and innovative is to establish the mechanism of ability layering and motivating, to guide students making benign competition. The bidding of innovative project is to compare the depth of technical literature review and the merits of technology solutions in the declaration.

Teaching methods. In the mode of teaching, the core is to establish the coupled teaching mechanism of inquiry learning and reception learning, the key is to distinguish the extent and boundaries between inquiry learning and reception learning in the process of penetration. At present, the analogous example is that numerous universities are trying to request the students of science and engineering to take some courses belong to humanities so as to solve the problem of the tendency of specialization.

However, as the founder of the general system theory notes that adding various aspects course cannot cultivate literacy also cannot bring a liberal education. The feasible way is, on the one hand, strengthening the engineering general basis, providing students with engineering association of humanities and social sciences courses, and teaching the students the knowledge that engineering activities involved, on the other hand, applying the project type teaching method to traditional classroom teaching, sharing the co-operative project, innovating the course content, adjusting the course structure and cultivating students' engineering ability in integrated way.

The first principle of the choice of teaching methods should be to create autonomous collaborative learning environment and multiple interactive communication mechanism for students. The specific 
implementation will vary from person to person, adjust measures to local conditions and well take example by the teaching practice of peers.

Assessment method. The assessment of engineering practice link should achieve coordination of training target and evaluation system. This is also one of the important works of this scenario teaching effect analysis. The purpose of evaluation is not only to activate the teaching activities, but also to promote the formation of students' unique learning method and the way of thinking and to promote the students' engineering ability. The set of evaluation index should be closely combined with the training objectives of engineering education professional certification standards, to realize personalized and diversified. The evaluation content should point to students' three aspects that is learning attitude, learning outcomes and results sharing, and the corresponding scores can be accounted for $40 \%, 30 \%$ and $30 \%$ respectively. The appraisal purpose of learning attitude is to guide students to develop their own initiative consciousness and innovation spirit, to establish a good style of study that both attach importance to process and pay attention to the results. The quality of learning outcomes can be evaluated from such aspects as the accumulation of knowledge and skills in the practice process and the progress and depth of the project. The ability check of all students' achievement sharing can use the form of project results reply to realize the technical exchanges and knowledge dissemination between different projects in a short time.

\section{Application method}

On the choice of training task object, it should be focused on such job types as the design and manufacture of mechanical products, mold design and the design, maintenance and sales of the mechanical equipment that the mechanical the mechanical professional students will be engaged in. Teachers can choose the laboratory existing mechanical structure, fixture and mould and other physical model resources, or choose home appliance products used in life such as mobile phone, desk lamp, fan, blower, etc. that is convenient for dismantling and easy access product reference structure. So to make the students at the beginning of the training can have a good interest and perceptual knowledge and can obtain the parameter data of design products through the actual surveying and mapping. In the selection of design software, it will be to guide students to master the differences between software, distinguish between types of integration software and function of single software, and understand the commonly used software function module. By the methods of data collection and research, understanding the application situation of product design and development software in current enterprise and guiding students to have a reasonable choice and use of popular computer aided software used in modern enterprise to finish the product development task.

In order to solve the problems of the training time is short, in the early stage of the implementation process of mechanical CAD/CAE/CAM training the target teaching method is used, the comprehensive training mission is issued in the initial and the content of the training mission is decomposed in pieces. In the process of theoretical teaching, combined with purposeful guidance task content, let the student active learning with the task and have task content thinking and software applications in the spare time of theory course learning. So as to make students have the basis of theory and software application in the beginning of the comprehensive training, to clarify the design task requirement, to selected good product development goals and complete the disassembling and surveying and mapping of product physical model.

According to the students' master situation of basic courses knowledge, combined with modern product development lifecycle process, an implementation process for the comprehensive training is designed, as shown in Fig. $3[4,5]$.

The specific content and requirements of each process link include:

(1) Reasonable selection of product development object. The product development object should consider the employment demand, and should be reasonably selected connecting with the personal interest. The product object cannot be too simple, the total number of parts or components are not less than eight, also cannot be too complex, and should have the actual product or model for your reference. 


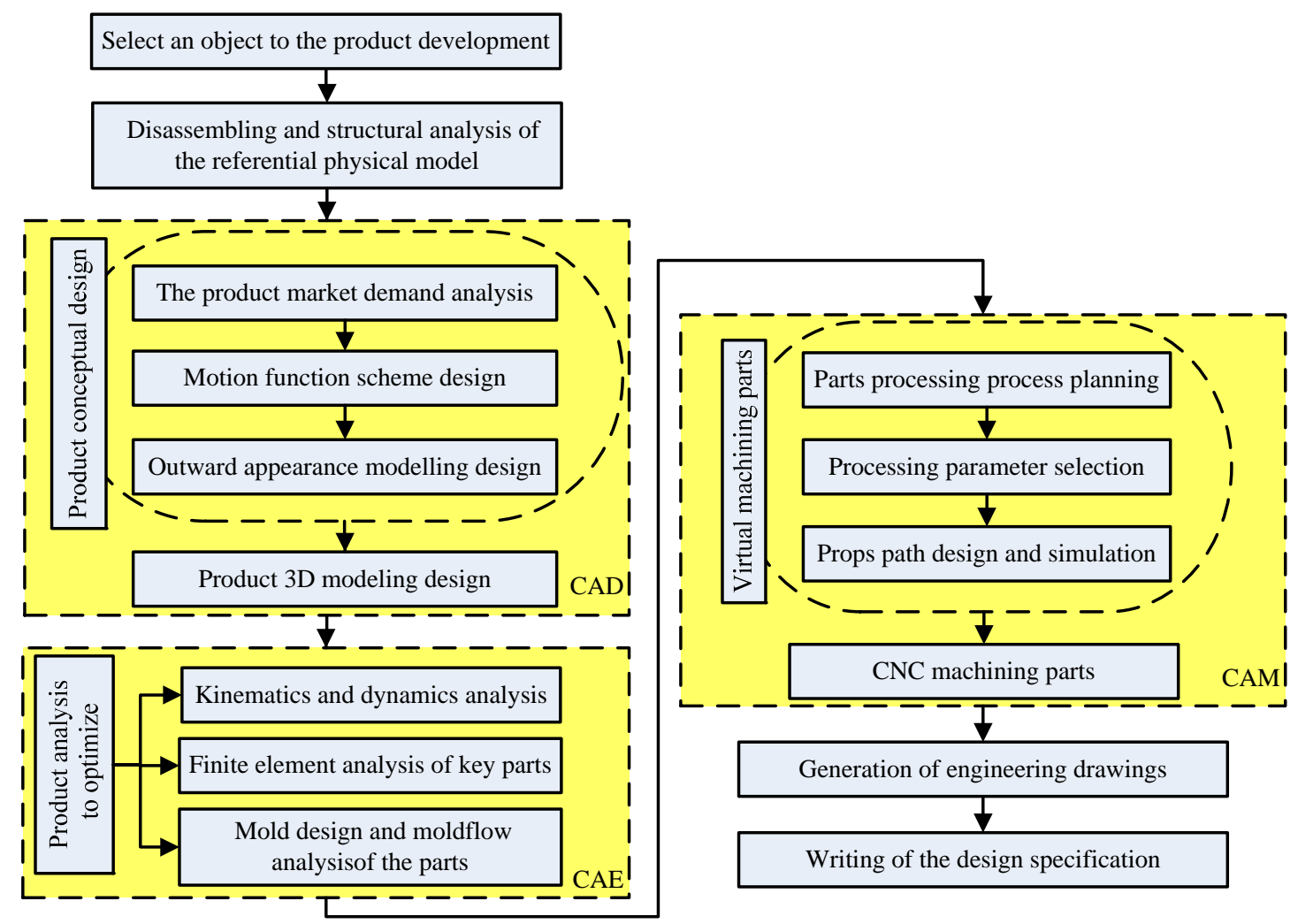

Fig. 3 The integrated implementation process of CAD/CAE/CAM technology based on the mechanical product development process

(2) Having certain innovative product conceptual design. The innovation design can be carried out from such angles as novelty, humanity and machinability of product function principle plan, motion mechanism scheme and appearance model. The results of concept design to product will be shown 3D digital model.

(3) CAD model design based on the physical product reference model. The disassembling and analysis should be carried out on the physical model for the selected product, avoid relying on network image data or personal imagination mechanism or structure and causing such problems as the error of mechanism motion principle or unreasonable structure, to ensure the rationality of the subsequent CAE analysis model. The product 3D CAD model and product structure model is established in view of the conceptual design scheme.

(4) Reasonable product CAE analysis. The problems of kinematics, mechanics or molding process exist in the actual use or manufacturing of the product objects will be analyzed. A certain problem of mechanism kinematic/dynamic, parts structure statics, parts die design or molding process is analyzed to carry out the analysis and optimization of the products.

(5) Virtual simulation machining of parts and NC machining of model. The typical parts of products is selected to analyze the characteristics of the parts and machining process planning, make machining process route and process parameters, plan the tool path, complete the simulation machining for each process and output NC code. The processing experiment is carried out by choosing materials such as wood or wax block, modifying the processing instruction, inputting NC machine tools, and finally processing shape parts.

(6) Drawing and document management. According to the requirements of national standard map product engineering, the product assembly drawing, explosion diagram and the various parts of engineering drawing are completed. A product design specification is written including product background and significance of its development, the main process and results of each section of CAD/CAE /CAM and comprehensive training summary, etc.

(7) The submission requirements. Each student should submit a paper specification for the product development, all electronic file related to CAD/CAE/CAM and a physical model for process parts. 


\section{Summary}

The practice teaching is organized based on project driven inquiry-reception type composite teaching idea, the four main line is closely centering on students as the main body, combining theory with practice, giving full play to students' subjective initiative and innovation consciousness. The mechanical professional courses combine theoretical knowledge and practical skills. It makes the student fully to participate in the whole process from project plan formulated to project implementation, to project tackling and finally to project results sharing. The goal of the optimization of mechanical professional teaching system, knowledge structure and essential skills, the development of the students' comprehensive practical ability, problem-solving ability and team cooperation ability is better achieved. Therefore, the reform has certain value of reference and transplantation for other professional engineering certification.

The implementation results of the curriculum design based on CAD/CAE/CAM technology show that with the employment as the guidance, the students' interest in learning is greatly improved by the comprehensive training based on the product development process, the ability to solve the problems such as the hardware or software development during the students' independent solve product development and design technique are enhanced, the initiative and enthusiasm of the students' innovation design is promoted, the mutual learning and exchanges between the students is accelerated, the students understanding of theoretical knowledge is further deepen, the students' ability of using CAD/CAE/CAM technology to solve the product development problems is improved and the students' employment competitiveness is well enhanced.

\section{Acknowledgement}

This research is funded by the Higher Education Research Projects of Lanzhou University of Technology, the Provincial Science Foundation of Gansu (1606RJZA166), and the Tutor Fund Project of Gansu Education Department (2014-A-029).

\section{References}

[1] D. Yang, R. Guo, Construction of Professional Curriculum System Based on Engineering Application Ability Training, 2014 International Conference on Management, Education, Business, and Information Science (ICMEBIS 2014), Shanghai, China, 2014.

[2] W. Jia, Building of engineering ability system about applied mechanical talents under background of engineering education certification, Experimental Technology and Management. 32(2015) 38-41.

[3] G. Chen, R. Du, The practice teaching of mechanical specialized courses based on engineering education professional certification, Teaching and Higher education BBS. 01(2015) 108-109.

[4] H. Xia, W. Zhen, H. Wang, et.al. Study on practical teaching method of mechanical $\mathrm{CAD} / \mathrm{CAE} / \mathrm{CAM}$ integrated training based on enterprise product development process, Experimental Technology and Management. 32(2015) 182-185.

[5] W. Shi, L. Wang, Y. Sun, et.al. Exploration on the teaching reform of mechanical CAD/CAE/CAM course under the background of applied undergraduate education, Science \& Technology Vision. 30(2015) 176-177. 